\title{
The relationship between teamwork and empowerment to patient satisfaction in orthopedic settings: An exploratory study
}

\author{
Paul Bruning1, Timothy Baghurst ${ }^{2}$ \\ ${ }^{1}$ Summit Orthopedics, Woodbury, MN \\ ${ }^{2}$ Oklahoma State University, Stillwater, OK
}

\section{Email address:}

Brunip42511@gmail.com (P. Bruning)

\section{To cite this article:}

Paul Bruning, Timothy Baghurst. The Relationship between Teamwork and Empowerment to Patient Satisfaction in Orthopedic Settings: An Exploratory Study. American Journal of Health Research. Vol. 1, No. 3, 2013, pp. 86-94. doi: 10.11648/j.ajhr.20130103.18

\begin{abstract}
Purpose - Health care reform mandates public reporting of patient satisfaction ratings which are used by both payers to establish reimbursement and by patients to evaluate and select providers for specialty care. Improving patient satisfaction ratings offers the potential to increase market share, reimbursement rates, and patient retention. Therefore, the purpose of this study was to measure the relationship between employee ratings of teamwork and empowerment and patient satisfaction scores at 14 orthopedic outpatient settings in the North Central Region of the United States. Design/methodology/approach - This study employed a quantitative, correlational approach. Surveys of employee perceptions of teamwork and empowerment were compared to patient satisfaction survey scores for strength and direction of correlation. Regression analysis measured the degrees of strength and correlation between subset scores of teamwork and empowerment to the patient satisfaction scores.Findings - There was a strong correlation between patient satisfaction and employee ratings of teamwork with a weak correlation between patient satisfaction and employee ratings of empowerment. Empowerment subsets of support and job activity scale demonstrated statistical significance toward patient satisfaction. Teamwork subsets of team structure, communication, and monitoring significantly impacted patient satisfaction. Research limitations/implications - The sample size of clinics proved small for greater application or generalizability. However, this research provides valuable information for further research and provides healthcare leaders information for possible adaptation to improve market sharePractical implications - Findings suggest that health care leaders can potentially increase patient satisfaction by making efforts toimprove teamwork. Improvement of teamwork can be achieved by specifically addressinghow teams understand their individual roles and how individuals can help each other when workload increases.Originality/value -This study provides a practical understanding of how staff cohesiveness positively influences patient satisfaction which may improve market share through patient retention.
\end{abstract}

Keywords: Empowerment, Teamwork, Patient Satisfaction, Leadership

\section{Introduction}

Demands on health care continue to grow as the population ages. The population within the United States continues to age as Baby-Boomers (those born between 1946 and 1964) account for more than 250 million or $11.3 \%$ of the population in 1993 (Berkowitz, 2006). The Congressional Budget Office predicted in 2010 that health care costs were expected to reach $25 \%$ of the economy by 2025 (Washington Post, 2010). Baby-Boomers will drive the health care economy requiring increasing levels of care beyond 2040 (Interplay, 2005). According to Press Ganey
(Interplay, 2005) and the results of nearly two million patient satisfaction surveys, “...the Baby Boom generation... as a whole is less satisfied than patients in the adjacent age groups. Members of the Baby Boom generation have been described as distrustful of institutions, more informed than others, and harder to please because of their high expectations" (p. 4).

Increases within the Baby Boomer population amplify demands on orthopedic facilities through larger demand for services. Intensification of workflow demands requires teamwork, and meeting expectations of Baby Boomers 
proves challenging for orthopedic facilities.It is logical to suggest that teamwork improves employee satisfaction, which in turn improves patient satisfaction, but little research has been done to establish a direct link between teamwork, employee empowerment, and patient ratings of satisfaction (Buljac-Samardzic, Dekker-van Doorn, van Wijngaarden, \& van Wijk, 2010; Tepeci, 2008; Zelster \& Nash, 2010). Developing patient loyalty requires going beyond simple patient satisfaction (Barger \& Grandey, 2006; Berkowitz, 2006; Interplay, 2005; Paula, Long, \& Wiener, 2002; Snipes, Oswald, LaTour, \& Armenakis, 2005). A Gallup finding (Interplay, 2005) indicated one for-profit health system increased its yearly earnings of $\$ 95$ million when ranked in the top-quartile of patient loyalty over lower quartile ranking hospitals. Therefore, health care leaders who provide services which exceed patient expectations will improve market share and patient loyalty (Deitrick, Capuano, Paxton, Stern, Dunleavy, \& Miller, 2007; Interplay, 2005).

As the population ages and economic factors influence individual finances, the rising cost of health care increases patient expectations and anxiety. Patients are demandingmore from their health care experiences and are expectinghigher levels of quality (Berendsen, de Jong, Meyboom-de Jong, Dekker, \& Schulling, 2009; Schneider \& Eisenberg, 1998). Therefore, information derived from patient experiences can be used to identify gaps in communication, teamwork, and quality (Browne, Roseman, Shaller, \& Edgman-Levitan, 2010). Improving patient experiences necessitate work standards, systems, and teamwork between staff members (Browne et al., 2010). The development of teamwork and communication between health care providers has been lacking in medical education as most health care provider education does not include any formal training processes (Leggat, 2007; Leonard, Graham, \& Bonacum, 2004). Development of teamwork and the empowerment of employees to generate improvements in patient ratings of satisfaction require health care leadership's attention. This study serves to investigate the relationship between employee ratings of teamwork, employee ratings of empowerment, and patient satisfaction scores of orthopedic outpatient settings in the North Central Region of the United States.

The concept of teamwork in health care does not involve only the provider and clinical support. Teamwork extends to every level of an organization including professional staff, administration, and support staff (Chesluk \& Holmboe, 2010; Zeltser \& Nash, 2010). Teamwork concepts cannot be isolated to care teams, but must be examined in the context of the entire health care organization.

Various teamwork development programs exist. For example, Crew Resource Management (CRM) has been employed in aviation since the 1970s to improve safety and develop teamwork (Leonard et al., 2004). CRM training became increasingly incorporated into health care to improve teamwork, communication, and safety
(Buljac-Samardzic et al., 2010; McConaughey, 2008; Zeltser \& Nash, 2010). The Department of Defense (DoD) programs are frontrunners with respect to the development of teamwork, and attempts to implement teamwork training in military hospitals (Sorbero, Farley, Mattke, \& Lovejoy, 2008). The DoD modeled its programs on the aviation industries CRM training (Buljac-Samardzic et al., 2010; McConaughey, 2008; Sorbero et al., 2008; Weaver et al., 2010; Zeltser, \& Nash, 2010).

Health care continues to grow in specialization while becoming more complex in organizational structure. Because of the complex nature of health care, an increasing number of practitioners are in practice together, and the growing group-based decisions involved in health care teamwork and employee empowerment are vital for health care organizations to develop (Leonard et al., 2004; Maynard, Mathieu, Marsh, \& Ruddy, 2007). Sax and colleagues (2009) found CRM training to influence personal behaviors and provide employees with a sense of empowerment. Spreitzer (1995) described four components of employee empowerment; meaning, competence, self-determination, and influence. Meeting all four components of empowerment requires health care leadership attention.

Health care leaders who build employee empowerment can improve the work environment and employee level of job satisfaction. Empowerment improves employee autonomy, organizational commitment, and self-efficacy (Laschinger, 2008). Employees who are not empowered are less engaged in providing quality services (Vandenberghe, Michon, Trembly, Bentein, Chebat, \& Fils, 2007). Vandenberghe et al. reported positive links between climate of the service, discernment of empowerment, and customer perceptions of quality. The empowered employee is more likely to respond to challenges, work efficiently, be satisfied in his or her work, and provide higher levels of patient care (Laschinger, 2008; Tepeci, 2008). Employees cultivate perceptions of organizational support and empowerment that correlates to job satisfaction (Laschinger, 2008; Vandenberghe et al., 2007). The foundation for employee commitment is developed from the perception of how much the organization cares for the employee (Vandenberghe et al., 2007). Thus, increasing this sense of organizational commitment to the employee provides the basis for personal empowerment.

Patient satisfaction proves a major issue in health care organizational financial and outcomes performance. An issue in health care is satisfaction with a patient-care experience, and apparent levels of quality are based on perceptions and attitudes that have a critical influence on a health care organization's performance (Berendsen et al., 2009; Browne et al., 2010; Interplay, 2005; Schneider \& Eisenberg, 1998). Patient satisfaction is a key measure in health care, and the patient experience is an important predictor of rated quality of care (Berendsen et al., 2009; Browne et al., 2010; Schneider \& Eisenberg, 1998).

Although teamwork improves employee satisfaction, 
which in turn improves patient satisfaction, there has not been a direct link established between teamwork and patient satisfaction (Buljac-Samardzic et al., 2010; Tepeci, 2008; Zelster \& Nash, 2010). Teamwork has been implied in medical education but is not a standard educational component (Leggat, 2007). Employees who are empowered provide higher levels of quality care (Laschinger, 2008; Tepeci, 2008). The relationship, however, between employee empowerment, service delivery, and service quality remains unclear (Snipes et al., 2004). Health care leaders and providers who recognize the value of patient satisfaction reduce cost to the health care organization.

Unsatisfied patients add cost to the system through repeated visits to various providers until he or she receives perceived adequate quality care. This perception of value influences the patient demand on resources. Patients seeking out several physician consultations results in an increase in the total cost of care for each visit, which in turn multiplies the cost to the individual's insurance carrier. Individuals whose expectations remain unmet consume resources and place strain on the health care system by demanding access to specialists. Limited access results in delayed care for individuals who require specialized care. These delays enhance disease process requiring additional resources and increased cost when the individual gains access to the system.

Teamwork in health care provides for a safer patient care experience. Reduction of errors saves valuable resources and increases patient satisfaction. Health care leaders who understand thevalue of teamwork will improve patient safety and the work environment. The concept of hierarchical decision-making cannot continue in health care. The aviation industry demonstrated the value of teamwork in the form of CRM. Health care research demonstrates the value of teamwork. The gap in research evident from the literature review occurs from no direct correlation between teamwork and patient satisfaction. Based on this gap in the literature, the purpose of this study was to investigate the relationship between employee ratings of teamwork, employee ratings ofempowerment, and patient satisfaction scores of orthopedic outpatient settings in the North Central Region of the United States. Because this was an exploratory study, three hypotheses within this setting were posited. First, H1a: A statistical correlation exists between the relationships of employee perception of teamwork scores on T-TPQ and patient ratings of satisfaction. Second, H2a: A statistical correlation exists between the relationships of employee perception of empowerment scores on CWEQ II and patient ratings of satisfaction. Third, H3a: A statistical correlation exists between the relationships of employee perception of empowerment scores on CWEQ II, and employee perception of teamwork scores on T-TPQ with patient ratings of satisfaction.

The general problem is to construct a connection between employee ratings of teamwork, employee ratings of empowerment, and patient satisfaction scores of orthopedic outpatient settings in the North Central Region of the United States.Employee empowerment and teamwork have been demonstrated to positively influence patient perceptions of value or quality of care (Buljac-Samardzic et al., 2010; Tepeci, 2008; Zelster \& Nash, 2010).Development of mandatory reporting of patient satisfaction ratings influences health care organization reimbursement (Barger \& Grandey, 2006; Berendsen et al., 2009; Berkowitz, 2006; Browne et al., 2010; Interplay, 2005; Schneider \& Eisenberg, 1998).

Patient care experiences determine loyalty to a health care organization and the perception of patient care experiences influence reimbursement and financial position (Barger \& Grandey, 2006; Berendsen et al., 2009; Browne et al., 2010; Berkowitz, 2006; Interplay, 2005; Paula et al., 2002; Schneider, \& Eisenberg, 1998; Snipes et al., 2005).The Patient Protection and Affordable Care Act (PPACA) of 2010 used the term "value" more than 200 times within the legislation (Feeley, Shafer Fly, Albright, Walters, \& Burke, 2010).The metrics of outcomes, efficiency, costs, and patients' perceptions of care are mandated for public reporting starting in 2014 (Feeley et al., 2010; Patient Protection and Affordable Care Act, 2010).Therefore, leadership must understand the components of value and patients perceptions of value (Feeley et al., 2010). Health care leaders who correlate components of employee perception of teamwork, employee perception of empowerment, and patient ratings of satisfaction are equipped to improve their organization's potential for success.

To date, it is unclear how employee perceptions of empowerment, employee perceptions of teamwork, and patient ratings of satisfaction in outpatient or ambulatory care settings influence each other.Organizations are increasingly using team-based approaches to meet changes in work environments (Maynard et al., 2007) which can improve quality, enhance customer satisfaction, and improve an employee's work experience through empowerment (Tepeci, 2008).The relational connections between staff teamwork and empowerment and its effect on patient satisfaction in outpatient settings have not been previously evaluated (Buljac-Samardzic et al., 2010; Tepeci, 2008; Zelster \& Nash, 2010).

\section{Methods}

\subsection{Participants}

One hundred and fifty three orthopedic centers were contacted from across the North Central Region of the United States to determine willingness to participate in the research study. This variability tentatively permits the generalization of the population surveyed to other orthopedic centers in the United States. The states included in the region were Ohio, Indiana, Michigan, Illinois, Wisconsin, Minnesota, Iowa, and North and South Dakota. Of the 153 clinics contacted, 14 agreed to participate yielding 776 individual participant responses. 


\subsection{Instruments}

The service quality (SERVQUAL) tool is a customer satisfaction, Likert-type scale survey.SERVQUAL (Parasuraman, Zeithamal, \& Berry, 1988) measures a rating of patient satisfaction. SERVQUAL provides a valid predictor of service quality. An adjustment to measure context, such as identifying the orthopedic setting in question, improves the validity of the tool (Carrillat, Jaramillo, \& Mulki, 2007). Reliability and validity of SERVQUAL have been demonstrated in retail settings (Parasuraman et al., 1988). SERVQUAL measurement follows Fottler, Ford, andHeaton (2009) in establishing the perceived levels of satisfaction with the entire patient-centered encounter, including competence, reliability, responsiveness, access, and expectations (Parasuraman et al., 1988).

A Likert-type scale provides numerical representation for responses to the 22 SERVQUAL survey questions. These responses include: 1) strongly disagree, 2) disagree, 3) neither disagree or agree, 4) agree, and 5) strongly agree. Each question was calculated as an average response from the specific clinic. The aggregate totals for each of the 22 survey questions provide a numerical representation for the rating of patient satisfaction for each clinic. The rating range for patient satisfaction is 22 to 110 . This scoring provides a numerical representation that permits correlational analysis with other measurement tools used in this study.

CWEQ II. The Conditions of Work Effectiveness Questionnaire-II (CWEQ-II) provides a modified 19 item tool of the original CWEQ. Both questionnaires were designed and validated by Laschinger, Finegan, Shamian, and Wilk (2001b). It consists of 19 items based on the six structural empowerment elements described by Kanter (1993), which includes opportunity, information, support, resources, formal power, and informal power. The six subscales, containing three to four items each, are summed to create a total score of empowerment (Laschinger, Finegan, \& Shamian, 2001a; Laschinger et al., 2001b). Each question requires a response based on a Likert-type scale of (1), none, to (5), a lot. Responses on each of the subscales are summed and then averaged to create a subscale score of one to five (Laschinger et al., 2001b). Each of the subscale scores are summed to create a total empowerment score (Laschinger et al., 2001b). Scores on the CWEQ II scale range from 6-30 with higher perceptions of empowerment represented byhigher values (Laschinger et al., 2001b). This scoring enables a numerical representation that permits correlational analysis to scores from other tools used in this study.

T-TPQ. The TeamSTEPPS Teamwork Perceptions Questionnaire (T-TPQ) comprises of 35 questions separated into five constructs that measure how the current state of teamwork within an organization is perceived. Its core components of teamwork are team structure, leadership, situation monitoring, mutual support, and communication
(AIR, 2010). The T-TPQ uses self-assessment to determine and indicate a value for individual perception of teamwork. Cognitive interviews, small group trial, and field testing helped direct the development of T-TPQ questions, and reliability coefficients for each construct range from .88 to .95 (AIR, 2010).

\subsection{Procedure}

Following Institutional Review Board approval prospective clinics were contacted through several methods and yielded a total of 14 clinics willing to participate. Initial letters stating the purpose of the research study were sent to Chief Operating Officers at orthopedic centers across the North Central Region of the United States. Further contact was made through LinkedIn postings, personal contacts, and e-mails to members of the American Association of Orthopaedic Executives within the Region studied. An introductory letter was sent to 153 orthopedic clinics which were identified by Google search. Included with the introductory letter was a copy of the IRB approval, permission to use premises form, and a copy of the informed consent to be signed by each participant (patient or employee) for the individual clinics. Once these documents had been signed, clinics were sent a packet containing the surveys. Employee packets included the informed consent, CWEQ-II, and T-TPQ. Patient packets included an informed consent and SERVQUAL. Each survey contained an individual identification number permitting reconciliation of the appropriate surveys to informed consent. The identification number also allowed exclusion of those individuals who later did not want their survey results included in the research. Two patients later requested removal from the studyand their results were removed prior to statistical analysis. Data of employee perception of teamwork and empowerment was collected on the same day as patients' perceptions of service quality, as employee perception of teamwork and empowerment may fluctuate. Once survey results were obtained at the clinical site, participating clinics packaged materials into pre-paid and tracked postage. Clinical administrators contacted the researcher permitting tracking of questionnaires returned.

\subsection{Data Analyses}

To determine if a relationship existed among the three variables, the data was analyzed using Pearson's correlation coefficient with alpha level set at $\mathrm{p}<.05$. A correlation coefficient provides a number from -1 to +1 where correlation strength increases as the value nears the limit of -1 or +1 .(Leedy \& Ormrod, 2010; Salkind, 2009). Each hypothesiswas evaluated using the Pearson's correlation coefficient to identify potential positive or negative relationships and strengths of these relationships. Additional analysis was conducted using multiple regression to compare the strength of the relationships between the independent variables subsets and the 
dependent variable of patient satisfaction.

\subsection{Results}

Correlation of the larger constructs of independent variables (Teamwork and Empowerment) to the dependent variable (Patient Satisfaction) provides for the relevance of further analysis of data through regression analysis of the subsets of Teamwork and Empowerment. Clinical locations' employee numbers varied as well aspatients completing the surveys on the same day. Aggregate averages were used for comparison amongst clinic locations. Data aggregates for each clinical location permitted correlational analysis.

Table 1. Clinic Aggregate Totals

\begin{tabular}{cccc}
\hline Clinic & CWEQ-II & T-TPQ & Pt Sat. \\
\hline 1 & 21.6 & 23.6 & 103.9 \\
2 & 18.8 & 18.3 & 99.1 \\
3 & 18.8 & 17.4 & 96.0 \\
4 & 21.4 & 20.2 & 98.1 \\
5 & 21.8 & 20.6 & 104.4 \\
6 & 19.6 & 16.4 & 91.5 \\
7 & 17.4 & 16.5 & 93.3 \\
8 & 18.2 & 17.7 & 94.9 \\
9 & 19.5 & 18.3 & 96.8 \\
10 & 15.6 & 17.7 & 98.3 \\
11 & 22.1 & 19.4 & 89.4 \\
12 & 14.3 & 18.0 & 91.1 \\
13 & 19.1 & 18.2 & 101.0 \\
14 & 20.8 & 18.6 & 99.9 \\
\hline
\end{tabular}

Correlations were obtained using the SPSS ${ }^{\circ}$ software. While teamwork and patient satisfaction were strongly correlated (.605), the constructs of empowerment and patient satisfaction were weakly correlated (.359). The independent variables of empowerment and teamwork also demonstrated a moderate correlation (.597) (Table 2).

Table 2. Pearson Correlations

\begin{tabular}{lc}
\hline & Patient Satisfaction \\
\hline Empowerment & 0.359 \\
Sig. (2-tailed) & 0.207 \\
Teamwork & 0.605 \\
Sig. (2-tailed) & 0.022 \\
\hline
\end{tabular}

This relationship of teamwork to patient satisfaction occurs as the slope of the line for teamwork (T-TPQ) increases more quickly than the slope of the line for empowerment (CWEQ-II; Figure 1). Each point indicates a clinic's patient satisfaction score against either the clinic's CWEQ-II or T-TPQ score. Clinics with higher T-TPQ scores demonstrated higher patient satisfaction scores. While the same was true for CWEQ-II, the slope of the line is smaller corresponding to the decreased correlation.

\subsection{Secondary Analysis}

The T-TPQ evaluates individual employee perceptions toward the subset scores of team structure, leadership, mutual support, situation monitoring, and communication. Individual employees rated each subset question on a Likert-type scale ranging from one to five. The average subset score for each individual employee was aggregated into the average score for each subset for individual clinics (Table 3).

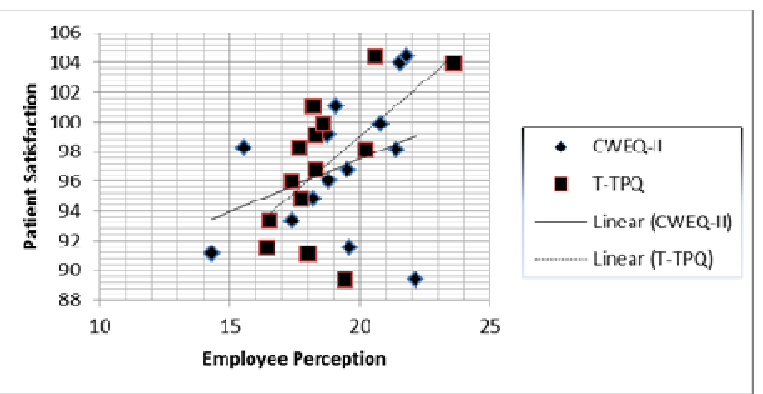

Figure 1. Scattergram of Clinic Aggregate Scores

Table 3. Aggregate Empowerment Subset Totals

\begin{tabular}{lllllll}
\hline $\begin{array}{l}\text { Clin } \\
\text { ic }\end{array}$ & $\begin{array}{l}\text { Opportu } \\
\text { nity }\end{array}$ & $\begin{array}{l}\text { Informat } \\
\text { ion }\end{array}$ & $\begin{array}{l}\text { Suppo } \\
\text { rt }\end{array}$ & $\begin{array}{l}\text { Resour } \\
\text { ces }\end{array}$ & $\begin{array}{l}\text { Job } \\
\text { Activiti } \\
\text { es Scale }\end{array}$ & $\begin{array}{l}\text { OR } \\
\text { S }\end{array}$ \\
\hline 1 & 4.28 & 3.56 & 3.89 & 3.39 & 3.28 & 3.17 \\
2 & 3.70 & 2.82 & 3.12 & 3.17 & 2.89 & 3.08 \\
3 & 3.79 & 2.75 & 3.35 & 2.96 & 3.05 & 2.90 \\
4 & 3.98 & 3.04 & 3.89 & 3.81 & 3.68 & 3.00 \\
5 & 4.08 & 3.88 & 4.00 & 3.08 & 3.38 & 3.41 \\
6 & 3.83 & 3.00 & 3.17 & 3.33 & 3.67 & 2.63 \\
7 & 3.53 & 2.67 & 2.57 & 3.20 & 2.63 & 2.79 \\
8 & 3.80 & 2.87 & 2.80 & 2.67 & 2.93 & 3.15 \\
9 & 3.79 & 3.19 & 3.11 & 3.29 & 3.16 & 2.99 \\
10 & 3.07 & 1.53 & 2.87 & 3.13 & 2.67 & 2.30 \\
11 & 4.33 & 3.93 & 3.47 & 3.13 & 3.67 & 3.60 \\
12 & 3.33 & 2.00 & 2.00 & 2.67 & 2.33 & 2.00 \\
13 & 3.81 & 2.98 & 3.05 & 3.07 & 3.04 & 3.13 \\
14 & 3.59 & 3.04 & 3.52 & 3.96 & 3.46 & 3.24 \\
\hline
\end{tabular}

Statistical analysis of the various subsets of the independent variables permits determination of which subsets have relationships and to what strength toward the dependent variable. Empowerment demonstrated a correlation of .359 toward patient satisfaction. Although empowerment was not significant $(p=.207)$ towards patient satisfaction, the analysis of the individual subsets towards patient satisfaction proves appealing for determination of subsets with greater influence on employee perception of empowerment (Table 4). Linear regression identified two subsets of empowerment as statistically significant when compared to patient satisfaction. Those subsets included Support $(p=.006)$ and Job Activity Scale $(p=.029)$. Empowerment as a construct was not significant compared to patient satisfaction, but certain subsets compared to patient satisfaction demonstrated statistically significant strength and relationship.

Teamwork $(p=.022)$ and its subsets $(p=.002)$ were both significant against patient satisfaction. Regression analysis identified three subsets of teamwork as statistically significant in relation to patient satisfaction: team structure 
$(p=.021)$, mutual support $(p=.000)$, and communication $(p$ $=.003)$.

Table 4. Aggregate Teamwork Subset Totals

\begin{tabular}{cccccc}
\hline Clinic & $\begin{array}{c}\text { Team } \\
\text { Struct } \\
\text { ure }\end{array}$ & $\begin{array}{c}\text { Leaders } \\
\text { hip }\end{array}$ & $\begin{array}{c}\text { Situation } \\
\text { Monitori } \\
\text { ng }\end{array}$ & $\begin{array}{c}\text { Mutual } \\
\text { Support }\end{array}$ & $\begin{array}{c}\text { Communicat } \\
\text { ion }\end{array}$ \\
\hline 1 & 4.88 & 4.57 & 4.48 & 4.83 & 4.83 \\
2 & 3.79 & 3.65 & 3.51 & 3.62 & 3.73 \\
3 & 3.69 & 3.56 & 3.22 & 3.33 & 3.61 \\
4 & 4.19 & 4.20 & 3.79 & 3.98 & 4.06 \\
5 & 4.00 & 4.16 & 3.88 & 4.27 & 4.29 \\
6 & 3.14 & 3.64 & 3.07 & 3.07 & 3.50 \\
7 & 3.50 & 2.68 & 3.37 & 3.35 & 3.64 \\
8 & 3.74 & 3.91 & 3.34 & 3.29 & 3.46 \\
9 & 3.75 & 3.63 & 3.62 & 3.56 & 3.78 \\
10 & 3.89 & 3.09 & 3.29 & 3.71 & 3.69 \\
11 & 4.09 & 3.94 & 3.66 & 3.71 & 4.03 \\
12 & 3.29 & 3.00 & 3.71 & 3.71 & 4.29 \\
13 & 3.63 & 3.36 & 3.55 & 3.73 & 3.93 \\
14 & 3.84 & 3.57 & 3.63 & 3.71 & 3.83 \\
\hline
\end{tabular}

\section{Discussion}

Demands on health care continue to grow as the population ages in the United States.Baby-Boomers (those born between 1946 and 1964) accounted for more than 250 million or $11.3 \%$ of the population in 1993 (Berkowitz, 2006). As a consequence, the rising cost of health care increases patient anxiety and ability to afford appropriate health care. In 2010, the Congressional Budget Office predicted health care costs are expected to reach $25 \%$ of the economy in 2025 (The Washington Post, 2010).

This study supports the theory that patient satisfaction is correlated to employee perceptions of teamwork. The H1a hypothesis is accepted. Specifically the subsets of team structure, mutual support, and communication proved statistically significant to correlations of patient satisfaction ratings. Those clinics with higher employee rated perceptions of teamwork demonstrated increased patient satisfaction ratings (Figure 1).

This study further demonstrated a mild correlation between patient satisfaction ratings and employee perceptions of empowerment, although the H2a hypothesis could not be accepted. Although the correlation was not statistically significant, two subsets of empowerment, support and job activities, proved statistically significant to patient satisfaction. Thus, employees with job activities that provide flexibility, innovation, and visibility or employees who feel supported with information and comments on improving performance demonstrated statistically significant correlations to increased patient satisfaction ratings.

Team communication deals with transfer of information, knowledge, ideas, or opinions between team members (Reader, Flin, Mearns, \& Cuthbertson, 2009). Studies demonstrate that communication reduces errors, provides value through improved efficiency, innovation, increases staff satisfaction, and increases patient satisfaction and confidence in the provider providing a patient-centered care delivery (Reader et al., 2009; Sevin, Moore, Shepherd, Jacobs, \& Hupke, 2009; Sutton, 2009). Improvements in communication nurture mutual support and respect between team members (Birk, 2011; Shea-Lewis, 2009). This study further supports prior research through the significant correlation between the constructs of communication and mutual support influencing patient satisfaction.

Understanding each team member's role permits more efficient cross-checking, coordination of care, contributions by individual team members, and improvements in situational awareness (Barach, 2007; Reader et al., 2009; Shea-Lewis, 2009; Sutton, 2009). Tension occurs as care team members attempt to balance excelling at their roles while meeting the needs the roles of others (Sevin et al., 2009). Understanding each team member's role, credentials, and the reduction of medical hierarchy reduces inflexibility of team members. Competition between team members results from tension, lack of flexibility, or understanding and promotion of other team members roles. Team structure influences the function and success of teams which, as shown from the present study, demonstrated a statistically significant influence on patient satisfaction $(p=.021)$.

An empowered employee works more efficiently, communicates better, and provides higher levels of quality care (Kuokkanen, Suominen, Harkonen, Kukkurainen, \& Doran, 2009; Laschinger, 2008; Maynard et al., 2007; Stewart, McNulty, QuinnGriffin, \& Fitzpatrick, 2010; Vandenberghe et al., 2007). They perceive empowerment differently, as they each require different information, support, and resources for their role. A great deal of research identifies employee empowerment and improvements in work environment positively affecting both employees and quality of care (Birk, 2011; Cho, Laschinger, \& Wong, 2006; Kuokkanen et al., 2009; Lautizi, Laschinger, \& Ravazzolo, 2009; Matthews \& MacDonald-Rencz, 2008; Ridley et al., 2009; Stewart et al., 2010; Tourangeau, Widger, Cranley, Bookey-Bassett, \& Pachis, 2009). Much of this research correlates the work environment to job satisfaction through perceptions of empowerment.

This study evaluated the relationships between employee perception of empowerment and patient ratings of satisfaction among orthopedic outpatient settings in the North Central Region of the United States. While a relationship exists $(r=.359)$ between employee perception of empowerment to patient satisfaction, it is not significant $(\mathrm{p}=.207)$.A reason that helps explain the relationship but lack of statistical significance may be due to the CWEQ-II and the construct validity found in relation to clinical outpatient settings. The construct validity of the empowerment score ranged from -0.69 to 0.95 . The construct validity questions in the CWEQ-II are global empowerment subscale questions intended to validate the total empowerment score. The challenge appeared that in certain clinics the global scale was reported much higher than average individual perceptions of empowerment. The 
empowerment survey was developed for nurses and in this case non-clinical staff such as front desk completed the survey. This could have decreased the construct validity to empowerment in terms of patient care and thus lowered the statistical significance of empowerment to patient satisfaction. Although it is understood that all interactions within the clinic influence patient satisfaction the non-clinical staff may assume they do not influence this perception and further analysis could benefit understanding this perception.

Although this study did not show a statistical significance in the relationship of empowerment perception and patient satisfaction, there was a positive correlation between empowerment and satisfaction, which encouraged the evaluation of the subsets of empowerment to patient satisfaction. Multiple regression of the individual subsets of empowerment demonstrated a statistical significance for support $(p=.006)$ and job activity scale $(p=.029)$. Support included questions on items regarding; things done well, things could be improved, and hints on problem-solving advice in current job. This support helps employees perceive empowerment and proves beneficial for patient satisfaction scores. The job activity scale asked questions regarding rewards for innovation, flexibility, and visibility of work related activities. Individuals want recognition for their efforts and appreciate a level of flexibility. These results are important for health care leaders, as they can help improve perceptions of empowerment through support, recognition, and flexibility. These subsets and actions directly and positively influence patient satisfaction levels.

Research indicates that teamwork and work environment promote employee sense of empowerment (Ridley et al., 2009; Sevin, et al., 2009; Shea-Lewis, 2009; Stewart et al., 2010). This study did not specifically evaluate teamwork influence on empowerment, but it did take a combined view of teamwork and empowerment on patient ratings of satisfaction. Each clinic's teamwork score was added to the empowerment score to create a combined score which was then correlated to the patient satisfaction scores. The combined score resulted in a .524 correlation that did not reach statistical significance $(\mathrm{p}=.055)$. This indicates that the combined score of teamwork and empowerment does not meet a statistical significance, yet does create a moderate level of correlation. Thus, the H3a hypothesis was rejected.

Although there was a small rate of return, this research demonstrates valuable information for health care leaders and future research. Several factors limited the participation rate. Primarily, there may have been survey fatigue and transparency issues. Several clinic administrators declined participation based on the potential for exposure of their clinics employee perceptions and patient satisfaction results. Some administrators feared potential public exposure of clinic employee engagement numbers. In addition, other administrators had recently completed their own employee engagement surveys or patient satisfaction surveys. These clinics indicated an unwillingness to participate due to the survey fatigue factor. Finally, clinics may have refused participation fearing the possible negative findings associated with their clinic. Additionally no financial incentives were provided for participation in this study.

\section{Conclusions}

Health care requires teamwork to provide high quality care. Teamwork and empowerment of employees increasesquality of care and reduces errors in medicine. As patient-centered care and reporting of patient perception of satisfaction increase, so does the expectation of patients on service standards. Research demonstrates the value of organizations improving patient satisfaction levels. Satisfaction increases trust levels in providers (Chu-Weininger \& Balkrishnan, 2006), improves patient-rated outcomes of care (Barham \& Devlin, 2011), and increases compliance with care processes including treatment and medications (Wickizer, Franklin, Fulton-Kehoe, Turner, Mootz et al., 2004). This exploratory study provides further evidence that employee perception of teamwork positively influences patient satisfaction ratings and warrants further investigation. Although employee perception of empowerment does not demonstrate statistical significance to patient satisfaction, the review of literature establishes a connection that this research supports in the Pearson correlation value identified.

Health care leaders influence relationships between the various stakeholders within the delivery system. This research demonstrates the value teamwork plays in improving patient satisfaction. Knowledge of this relationship provides significanceto the health care system through care delivery cost reduction, diminishes duplication of services, and enhances outcomes of treatment.

Future research needs to consider obtaining larger clinic sample sizes to determine whether these findings differ across various size organizations. In addition, future studies should investigate other health care specialties such as dermatology, cardiology, and primary care. Although this study demonstrates a correlation within orthopedics, the findings cannot be generalized to other specialties without further investigation. Geographic correlations would help to determine the influence of local cultural factors. In addition, evaluation of payer mix provides further guidance for health care leaders to provide high levels of care and improve employee output. Further studies that evaluate and compare geographic differences will assist in determining whether cultural influences or local customs induce employee perception of teamwork or empowerment and the resultant patient satisfaction level.

\section{References}

[1] American Institutes for Research (AIR). (2010). TeamSTEPPS teamwork perceptions questionnaire (T-TPQ) manual. 
[2] Barach, P. (2007). A team-based risk modification programme to make health care safer. Theoretical Issues in Ergonomics Science, 8(5), 481-494. doi: $10.1080 / 14639220701193116$.

[3] Barger, P. \&Grandey, A. (2006). Service with a smile and encounter satisfaction: Emotional contagion and appraisal mechanisms. Academy of Management Journal, 49(6), 1229-1238.

[4] Barham, L. \& Devlin, N. (2011). Patient-reported outcome measures: Implications for nursing. Nursing Standard, 25(18), $42-45$.

[5] Berendsen, A., de Jong, G., Meyboom-de Jong, B., Dekker, J., \&Schulling, J. (2009, April). Transition of care: experiences and preferences of patients across the primary/secondary interface - a qualitative study. BMC Health Services Research, 9(62).

[6] Berkowitz, E. (2006). Essentials of health care marketing, (2nd ed.), Sudbury, MA: Jones and Bartlett.

[7] Birk, S. (September/October, 2011). The patient safety team: Healthcare executives embrace their role. Healthcare Executive, 13-22.

[8] Browne, K., Roseman, D., Shaller, D., \&Edgman-Levitan, S. (2010). Measuring patient experience as a strategy for improving primary care. Health Affairs, 29(5), 921-925. doi: 10.1377/hlthaff.2010.0238.

[9] Buljac-Samardzic, M., Dekker-van Doorn, C., van Wijngaarden, J., \& van Wijk, K. (2010). Interventions to improve team effectiveness: A systematic review. Health Policy, 94, 183-195.

[10] Carrillat, F., Jaramillo, F., \&Mulki, J. (2007). The validity of the SERVQUAL and SERVPERF scales a meta-analytic view of 17 years of research across five continents. International Journal of Service Industry Management, 18(5), 472-490. doi: 10.1108/09564230710826250.

[11] Chesluk, B. \&Holmboe, E. (2010). How teams work - or don't - in primary care: A field study on internal medicine practices. Health Affairs, 29(5), 874-879.

[12] Cho, J., Laschinger, H., \& Wong, C. (2006). Workplace empowerment, work engagement, and organizational commitment of new graduate nurses. Nursing Leadership, 19(3), 43-60.

[13] Chu-Weininger, M.\&Balkrishnan, R.(2006). Customer satisfaction with primary care provider choice and associated trust. BMC Health Services Research, 6(139), 139-153. doi: 10.1186/1472-6963-6-139.

[14] Deitrick, L., Capuano, T., Paxton, S., Stern, G., Dunleavy, J., \& Miller, W. (2007). Becoming a leader in patient satisfaction. Health Marketing Quarterly, 23(3), 31-57. doi: $10.1080 / 07359680802086125$.

[15] Feeley, T., Shafer Fry, H., Albright, H., Walters, R., \& Burke, T. (2010). A method for defining value in healthcare using cancer care as a model. Journal of Healthcare Management, 55(6), 399-412.

[16] Fottler, M., Ford, R., \& Heaton, C. (2009). Achieving Service Excellence, Chicago, IL: Health Administration Press.

[17] Interplay, Inc. (2005). Beyond patient satisfaction: How compassion creates loyalty, Bellevue, WA.

[18] Kanter, R. (1993). Men and Women of the Corporation, (2nd ed.). New York, NY: Basic Books.

[19] Kuokkanen, L., Suominen, T., Harkonen, E., Kukkurainen, M., \& Doran, D. (2009). Effects of organizational change on work-related empowerment, employee satisfaction, and motivation. Nursing Administration Quarterly, 33(2), 116-124.

[20] Laschinger, H. (2008). Effect of empowerment on professional practice environments, work satisfaction, and patient care quality. Journal of Nursing Care Quality, 23(4), 322-330.

[21] Laschinger, H., Finegan, J., \&Shamian, J. (2001a). Promoting nurses' health: Effect of empowerment on job strain and work satisfaction. Nursing Economic\$, 19(2), $42-52$.

[22] Laschinger, H., Finegan, J., Shamian, J., \&Wilk, P. (2001b). Impact of structural and psychological empowerment on job strain in nursing work settings: Expanding Kanter's model. Journal of Nursing Administration, 31(5), 260-272.

[23] Lautizi, M., Laschinger, H., \&Ravazzolo, S. (2009). Workplace empowerment, job satisfaction, and job stress among Italian mental health nurses: An exploratory study. Journal of Nursing Management, 17, 446-452. doi: 10.1111/j.1365-2834.2009.00984.x.

[24] Leedy, P. \&Ormrod, J. (2010). Practical research planning and design, (9th ed.). New York, NY: Pearson.

[25] Leggat, S. (2007). Effective healthcare teams require effective team members: defining teamwork competencies. BMC Health Services Research, 7(17). (Available from http://www.biomedcentral.com/1472-6963/7/17).

[26] Leonard, M., Graham, S., \&Bonacum, D. (2004). The human factor: the critical importance of effective teamwork and communication in providing safe care. Quality Safe Health Care, 13(suppl 1), 85-90.

[27] Matthews, S. \& MacDonald-Rencz, S. (2008). Healthy workplaces and teamwork for healthcare workers need public engagement. Healthcare Paper, 7, 52-57.

[28] Maynard, M., Mathieu, J., Marsh, W., \& Ruddy, T. (2007). A multilevel investigation of the influences of employee's resistance to empowerment. Human Performance, 20(2), 147-171.

[29] McConaughey, E. (2008). Crew resource management in healthcare. Journal of Perinatal and Neonatal Nursing, 22(2), 96-104.

[30] Parasuraman, A., Zeithamal, V., \& Berry, L. (1988). SERVQUAL: A multiple-item scale for measuring consumer perceptions of service quality. Journal of Retailing, 64(1), $12-40$.

[31] Patient Protection and Affordable Care Act, Pub L No. 111-148, 124 Stat. 119. (2010).

[32] Paula, A., Long, R., \& Wiener, D. (2002). Are your patients satisfied. Marketing Health Services, 22(3), 30-33.

[33] Reader, T., Flin, R., Mearns, K., \&Cuthbertson, B. (2009). Developing a team performance framework for the intensive 
care unit. Critical Care Medicine, 37(5), 1787-1793. doi: 10.1097/ccm.0b013e31819f0451.

[34] Ridley, J., Wilson, B., Harwood, L., \&Laschiner, H. (2009). Work environment, health outcomes and magnet hospital traits in the Canadian nephrology nursing scene. Canadian Association of Nephrology Nurses and Technologists Journal, 19(1), 28-35.

[35] Sax, H., Browne, P., Mayewski, R., Panzer, R., Hittner, K., et al. (2009). Can aviation-based team training elicit sustainable behavioral change.Arch Surg, 144(12), 1133-1137.

[36] Schneider, E., \& Eisenberg, J. (1998). Strategies and methods for aligning current and best medical practices. Western Journal of Medicine, 168(5), 311-318.

[37] Sevin, C., Moore, G., Shepherd, J., Jacobs, T., \&Hupke, C. (2009). Transforming care teams to provide the best possible patient-centered, collaborative care. Journal of Ambulatory Care Management, 32(1), 24-31.

[38] Shea-Lewis, A. (2009). Teamwork: Crew resource management in a community hospital. Journal for Healthcare Quality, 31(5), 14-18.

[39] Snipes, R., Oswald, S., LaTour, M., \&Armenakis, A. (2005). The effects of specific job satisfaction facets on customer perceptions of service quality: An employee-level analysis. Journal of Business Research, 58, 1330-1339. doi: 10.1016/j.jbusres.2004.03.007.

[40] Sorbero, M., Farley, D., Mattke, S., \& Lovejoy, S. (2008). Outcome measures for effective teamwork in inpatient care. (Available from the RAND Corporation, 1776 Main St, PO Box 2138, Santa Monica, CA 90407-2138)

[41] Spreitzer, G. (1995). Psychological empowerment in the workplace: Dimensions, measurement, and validation. Academy of Management Journal, 38(5), 1442-1465.

[42] Steinberg, W. (2010). Statistics alive, (2nd ed.), Thousand Oaks, CA: Sage.

[43] Stewart, J., McNulty, R., Quinn Griffin, M., \& Fitzpatrick, J.
(2010). Psychological empowerment and structural empowerment among nurse practitioners. Journal of the American Academy of Nurse Practitioners, 22, 27-34. doi: 10.1111/j.1745-7599.2009.00467.x.

[44] Sutton, G. (2009). Evaluating multidisciplinary health care teams: Taking the crisis out of CRM. Australian Health Review, 33(3), 445-452.

[45] Tepeci, M. (2008, Spring). Customer service team effectiveness: An observational study. Journal of Travel and Tourism Research, 9-23.

[46] The Washington Post. (2010). Landmark the inside story of America's new health-care law and what it means for us all, New York, NY: Public Affairs.

[47] Tourangeau, A., Widger, K., Cranley, L., Bookey-Bassett, S., \&Pachis, J. (2009). Work environments and staff responses to work environments in institutional long-term care. Health Care Management Review, 34(2), 171-181.

[48] Vandenberghe, C., Michon, R., Trembley, M., Bentein, K., Chebat, J., \&Fils, J. (2007). An examination of the role of perceived support and employee commitment in employee-customer encounters. Journal of Applied Psychology, 92(4), 1177-1187. doi: 10.1037/0021-9010.92.4.1177.

[49] Weaver, S., Rosen, M., DiazGranados, D., Lazzara, E., Lyons, R., et al. (2010). Does teamwork improve performance in the operating room? A multilevel evaluation. The Joint Commission Journal on Quality and Patient Safety, 36(3), 133-142.

[50] Wickizer, T., Franklin, G., Fulton-Kehoe, D., Turner, J., Mootz, R., et al., (2004). Patient satisfaction, treatment experience, and disability outcomes in a population-based cohort of injured workers in Washington state: Implications for quality improvement. Health Services Research, 39(4), 727-748.

[51] Zeltser, M., \& Nash, D. (2010). Approaching the evidence basis for aviation-derived teamwork training in medicine. American Journal of Medical Quality, 25(1), 13-23. 